International Journal of Forensic Science \& Pathology (IJFP)

ISSN 2332-287X

\title{
Familial Poisoning by Phosphine
}

Case Report

\author{
Czeslaw Zaba ${ }^{1,4 *}$, Jerzy T. Marcinkowski ${ }^{2}$, Artur Tezyk ${ }^{1}$, Pawel Swiderski ${ }^{1}$, Zbigniew Zaba ${ }^{3}$, Aleksander Mularski ${ }^{1}$, Aneta Klimberg ${ }^{2}$ \\ ${ }^{1}$ Chair and Department of Forensic Medicine, Poznan University of Medical Sciences, Poznan, Poland. \\ ${ }^{2}$ Chair of Social Medicine, Poznan University of Medical Sciences, Poznan, Poland \\ ${ }^{3}$ Clinic of Anesthesiology, Intensive Care and Pain Management, Poznan University of Medical Sciences, Poznan, Poland \\ ${ }^{4}$ Jan Sehn Institute of Forensic Research - Laboratory for Road Accidents
}

\begin{abstract}
Lethal intoxications with phosphine belong to rare cases in Poland. Most frequently they involve suicidal intake of metal phospides and accidental intoxications due to gas inhalation. The case of acute intoxication with phosphine in presented, affecting two persons: a 14-month-old child, who died, and the surviving mother. The intoxication took place on a farm and phosphine was released from toxic aluminium phosphide, a component of Quickphos Pellets 56GE preparation, widely used for disinsection of empty facilities for storage of grain and other alimentary products. Autopsy of the 14-month-old child demonstrated cerebral edema and pulmonary edema and excluded other pathology as the cause of death. Toxicological tests demonstrated only elevated levels of phosphorus. The entire clinical pattern of intoxication permitted to conclude that the cause of 14-month-old child's death involved acute intoxication with phosphine, in the mother a subacute intoxication with phosphine was diagnosed. The survival of the mother and death of her 14-month-old child reflected their very different body weight and distinct resistance to toxic effect of phosphine.
\end{abstract}

Keywords: Phosphine Intoxication, Aluminum Phosphide, Pesticides, Death of a Small Child.

\section{*Corresponding Author:}

Czeslaw Zaba,

Chair and Department of Forensic Medicine, Poznan University of Medical Sciences, Poznan, Poland.

E-mail:czaba@ump.edu.pl

Recieved: May 07, 2014

Accepted: June 06, 2014

Published: June 11, 2014

Citation: Czeslaw Zaba et al (2014) Familial Poisoning by Phosphine. Int J Forensic Sci Pathol. 2(5), 34-37. doi: http://dx.doi. org $/ 10.19070 / 2332-287 X-1400011$

Copyright: Czeslaw Zaba ${ }^{\circ}$ 2014. This is an open-access article distributed under the terms of the Creative Commons Attribution License, which permits unrestricted use, distribution and reproduction in any medium, provided the original author and source are credited.

\section{Introduction}

Stored grain, its products, fodder, alimentary products and high protein raw materials, kept in magazines, siloses, elevators, barges and ship holds, are exposed to pests of various type, mainly insects, mites and rodents.

One of the most important ways of protection against the pests in farms involves application of gas-emitting plant protection agents. Magazines and products exposed to pests are subjected to gassing (fumigation). Phosphine involves one of the most widely applied gases, which destroys eggs, larvae, chrysalides and adult forms of all magazine pests, although in the gassed facilities rats and mice are also killed.

Preparations which generate phosphine include, i.a., QuickPhos Pellets 56 GE (pastilles) and QuickPhos Tablets 56 GE (tablets), containing aluminum phosphide which in reaction with air-con- tained water releases phosphine. The gas rapidly diffuses in air and penetrates very well various products to the depth of $15 \mathrm{~m}$, even through dense packing of the products.

Phosphine is a colourless gas, manifesting a sweet-nauseating, fish-like, garlic-like or carbide smell. It is slightly heavier than the air. Lethal intoxications with phosphine comprise infrequent cases of intoxication in Poland. Intoxications of children belong to exceptional cases. Cases of suicidal oral administration of aluminum or zinc phosphide are known $[4,5]$. Intoxications through inhalation represent most frequently unfortunate accidents.

\section{Aims of study}

The general aim of the study was to explain the difference in sequels of acute intoxication with phosphine manifested in two individuals exposed in the same conditions, in which 14-monthold child died while the mother developed only a subacute poisoning. The authors attempted to detect the pathway in which phosphine penetrated bodies of the victims and to demonstrate circumstances and causes of the intoxication. The case history should draw attention of readers to hazards linked to use of plant protection agents even when appropriate procedures of their use are observed.

\section{Case history}

In an afternoon of a September day in 2007 an employee trained in use of Quickphos Pellets 56 GE started to disinfect an area of a company called the grain-containing garage which was a fodder for animals. Apart from the production facilities, the building included a housing part, including a room for an owners' small child, situated just above the garage. The employee, before spreading the preparation, sealed all the inflow and outflow gaps and crevices in the garage, pasted and sealed the door between the garage 
and the housing facility and the garage gate. Within the first few hours nobody approached the gassed facility. In the evening, the mother with her 14-month-old child went to sleep to the room situated directly above the garage. Entering the room, the mother felt "a sweet smell" but she disregarded the impression. The child and the mother went to sleep around 8:00 p.m. and slept for 4.5 hours when the crying of the child woke up the mother. Within half-an-hour the mother with her child left the room due to child's vomiting and malaise in the mother. Although the mother and the child vacated the room they remained in the building and finally the child went to sleep again and slept till 7 a.m. next morning. After waking up, the child suddenly developed bluish colour of its body covers and an irregular breath. It was immediately taken by the father to the nearby situated ambulance station and, then, to a hospital, in which the child died during circulatory-respiratory resuscitation. The mother was hospitalized in a ward of toxicology because she exhibited symptoms of vertigo, nausea, vomiting and headache. In the course of investigations the room over the garage was found to be connected to the garage through a direct, unsealed small opening, containing thin copper pipes of central heating, running from an oven to a radiator in the child's room.

\section{Methodology}

\section{Autopsy}

The child's body was subjected to an autopsy 24 hours ater death and blood, urine, brain, liver with gallbladder and kidneys were taken for toxicological analysis and internal organs samples were also taken for histopathological investigations.

\section{Materials}

In the hospital the mother's blood sample was taken for toxicological examinations. All biological specimens were sent to the toxicological laboratory in the Department of Forensic Medicine, Poznan University of Medical Sciences. Three twist-type jars, containing a mixture of tablets and carbide-smelling powder, secured at the site of the preparation use (the garage) were also subjected to toxicological identification at the same laboratory.

\section{Methods}

The autopsy material (blood, urine and internal organs $1 \mathrm{ml}$ or $1 \mathrm{~g}$ ) and the blood supravitally obtained from the mother were homogenised, transferred into $20 \mathrm{ml}$ head-space vials, $10 \mathrm{ml} 10$ $\% \mathrm{H}_{2} \mathrm{SO}_{4}$ was added, vials were sealed and targeted tested for phosphine using head-space gas chromatography technique. Perkin Elmer TurboMatrix HS-40 headspace autosampler conncected with Perkin Elmer Clarus 500 gas chromatograph equipped with a Supel Q PLOT column (30 mx $0.32 \mathrm{~mm}$ ID, $15 \mu \mathrm{m}$ film thickness, Supelco, USA) were used. Both Nitrogen-Phosphorus Detector (NPD) and mass selective detector (MSD) were applied. No phosphine signal was found above established LOD $0,5 \mathrm{ng} /$ $\mathrm{ml}$.

A total phosphorus level in the blood samples was measured by inductively-coupled plasma mass spectrometry (ICP-MS XP 1500 Plus, Varian, USA) after microwave mineralisation.

Blood samples were checked for presence of carboxyhemoglobin and methemoglobin on Oximeter OSM3 (Radiometer, Denmark). Samples of blood and urine were subjected to toxicological analysis for volatile compounds by GLC and for drugs and pesticides using GC-MS and HPLC techniques, preceded by liquid/liquid extraction.

\section{Results}

The autopsy of the child's body showed signs of acute cerebral and pulmonary edema as well as possible sudden death because of liquid blood in the cardiac cavities and blood vessels. The autopsy excluded other pathology as a cause of death. Histopathology demonstrated traits of cerebral edema, acute pulmonary edema and foci of pulmonary emphysema as a sequel of artificial ventilation.

Results of the toxicological analysis of the blood and organ samples for phosphine presence were negative at limit of detection of the applied technique. Because of the negative result of phosphine analysis we have decided to measure total blood phosphorus level as an indicator of phosphine exposure. The measured levels of total phosphorus (table 1) are laying within normal range.

Blood samples were found negative for presence of carboxyhemoglobin and methemoglobin. Toxicological analysis of the blood and urine reveled neither volatile organic compounds nor common drugs. The substance secured in jars at the place of the event was identified as aluminium phosphide.

\section{Discussion}

QuickPhos preparation represents an insecticide, acarinecide, and rodenticide belonging to very toxic agents since it releases phosphine, the extremely harmful compound for living organisms. Pellets and tablets of the preparation are grey in colour, have hardly a detectable smell and contain around $56 \%$ aluminium phosphide, which reacts with air and moisture to release phosphine $\left(\mathrm{PH}_{3}\right)$. A single $0.6 \mathrm{~g}$ pastille of the preparation releases $0.2 \mathrm{~g}$ of phosphine while a tablet of $3 \mathrm{~g}$ releases $1 \mathrm{~g}$ of phosphine. The gas is a compound of low molecular weight and a low boiling temperature. It rapidly diffuses in air and manifests a very high penetrability of various products and materials. It reaches products and materials in sites where plant protection agents in other form have no access. Phosphine has properties including pronounced toxicity and excellent penetrability allowing the compound to have broad application in protection of products against various pests. Due to

Table 1. Total phosphorus contents in examined blood samples.

\begin{tabular}{|l|l|l|}
\hline Examined blood sample & $\begin{array}{l}\text { Phosphorus concentration } \\
{[\mathrm{mg} / \mathrm{ml}]}\end{array}$ & $\begin{array}{l}\text { Normal range for children } \\
{[\mathrm{mg} / \mathrm{ml}]}\end{array}$ \\
\hline Child & 0.608 & $0.40-0.70$ \\
\hline & & Normal range for adults \\
\hline Mother & 0.344 & $0.25-0.50$ \\
\hline
\end{tabular}


their very high toxicity, QuickPhos preparations should be applied exclusively by appropriately trained staff.

Symptoms of phosphine intoxication are non-specific. However, an evident difference can be noted between symptoms noted following inhalation (respiratory pathway) as compared to those seen following oral administration (alimentary pathway). Inhalation of phosphine irritates respiratory system, leading to circulatory insufficiency, depressive effects on the central nervous system, coma and death in the mechanism of respiratory insufficiency. Contact with even minimum doses of the fumigant should be avoided. Exposure to phosphine at the concentration of 1400 $\mathrm{mg} / \mathrm{m}^{3}$ (1000 ppm) may lead to death within $30 \mathrm{~min}$. The highest tolerable concentration and the highest momentary tolerable concentration for phosphine amount is 0.14 to $0.28 \mathrm{mg} / \mathrm{m}^{3}$, respectively. $[1,2,3,9,11]$.

Preliminary clinical symptoms of a benign exposure to phosphine may imitate upper respiratory infection. Other signs may include nausea, vomits, diarrhoea, headache, tiredness and vertigo. More pronounced exposure to the gas results in irritation of respiratory system with persistent cough, ataxia, paresthesia, tremor, diplopia. Jaundice may also develop. In very severe cases acute pulmonary oedema develops, arrythmia, seizures, cyanosis and coma. Oliguria or even anuria, proteinuria are noted. Death used to develop due to pulmonary edema with developing signs of renal and hepatic injury. Consumption of aluminium phosphide induces nausea, vomiting, sometime diarrhoea, retrosternal and abdominal pain, chest compression sensation, cough and vertigo. In severe cases a haemorrhage from alimentary tract, tachycardia, arterial hypotension, a disturbed cardiac rhythm, hypothermia or hyperthermia, metabolic acidosis, cyanosis, pulmonary edema, seizures and coma appear. In cases of children intoxication by inhalation develops very infrequently. Frequently are cases of alimentary intoxications and these are linked to accidental finding of the preparation in the place of a child's stay and consumption of the preparation $[5,6]$.

In epidemiological studies conducted in Germany in the years of 1983-2003, 188 cases of phosphine intoxication were noted, of which $65 \%$ were unintended and took place in apartments, $28 \%$ represented suicides, 5\% represented intoxications at work and $2 \%$ remained undefined. Much higher numbers of phosphine intoxications are noted in India and African countries, in which preparations containing or releasing phosphine are generally accessible. In Polish literature no epidemiological studies on phosphine intoxications were available, just casuistic descriptions of such intoxications could be located. $[3,4,8,9]$.

In the area of Poland, lethal intoxications with phosphine represent sporadic experience in the forensic practice. Most frequently, they represent unfortunate accidental inhalation or suicidal acts involving their purposeful consumption. The incidence of suicides involving consumption of aluminium phosphide is rising [5]. Most frequently, phosphine intoxication develops due to inappropriate safety measures taken by staff that uses the agent $[8,9]$.

As indicated by the literature of the subject and by press reports, death used to affect all the victims exposed to amplified concentrations of the extremely toxic gas. However, very few reports pertain to intoxications of children and it is not very frequent case when one of the individuals subjected to identical exposure to critical concentration of phosphine died while the other survived. The most frequently observed signs/symptoms in accidental intoxications involved nausea, vomits, pain, cough and vertigo, without subsequent exacerbation of the signs/symptoms. In the described case similar signs/symptoms had developed in mother of the child.

The autopsy of the child's body had disclosed no pathology other than cerebral and pulmonary edema. Histopathology had confirmed the macroscopically diagnosed lesions and excluded hepatic and renal lesions or other pathology, including inflammatory lesions. Pattern of such lesions is typically noted upon autopsy, as a sequel of toxic effects of phosphine. Inhalation of phosphine irritates respiratory system, leads to circulatory insufficiency, depressive effects on the central nervous system, coma and death.

The secured biological material has been subjected to targeted tests for presence of phosphine, the active compound released from QuickPhos tablet 56GE preparation which was used at the spot of the event. Although the toxicological tests failed to disclose the presence of phosphine, the absence of its original form may reflect its high reactivity, volatilty and prolonged period of exposition to the low concentration of phosphine. Furthermore as Musschoff noted [12], loss of phosphine during the time of death and autopsy and during sample storage may occur, especially when samples are not properly secured in airtight containers.

Determination of phosphorus contents showed no abnormal values in the blood of mother. In the case of the child's autopsy blood a high concentration of phosphorus was detected (in the upper normal range for children), which might reflect exposure to phosphine as well as effect of post-mortem changes. Tests on the child's blood have failed to detect carboxyhaemoglobin, methaemoglobin, or other compounds of exogenous origin.

Based on the clinical pattern of the intoxication the cause of death in the 14-month-old child was an acute intoxication with phosphine while in the child's mother only a subacute intoxication with the compound has been diagnosed.

The different effect of phosphine action on the mother and her child is because of their very different body weight. A small child, with body weight much lower than adults, suffers much more from exposure to the same concentration of the xenobiotic agent in atmosphere than an adult person. Newborns, infants and small children do not have developed inner organs, which still continue to develop and therefore, do not have the ability to detoxify as adults. Therefore, a toxic dose of phosphine is lower for a child than that for its mother. This might explain the lethal intoxication in the child and just a subacute intoxication in its mother.

In this case, it is evident that phosphine passed through a small opening between the gassed facility and the room with victims, situated above the former.

\section{Conclusions}

Using very toxic agents, procedures of their safe use should be rigorously observed. The process of gassing should be conducted exclusively by an appropriately trained staff, in line with producer's instruction. The fact of survival of an adult woman associated with death of her 14-month-old child reflected a marked difference in their body weight as well as immaturity of enzymatic system in the child and, linked to it, higher sensitivity to the xenobiotic agent. The presented case belongs to few reports of the type and, therefore, it might prove useful in preparing forensic 
expertises related to similar events.

\section{References}

[1]. Ignatowicz S(2011) Zwalczanie szkodników w metalowych silosach BIN i wokół nich [in Polish]. Szkoła Główna Gospodarstwa Wiejskiego, Katedra Entomologii Stosowanej 9/10 ul. Nowoursynowska 159 02-787 Warszawa 10, pp. 1-10.

[2]. Information leaflet on Quickphos Pellets 56 GE, http://www.ddd.agrosimex.pl/pdf/quickphos-pellets-56-ge_karta-charakterystyki.pdf.

[3]. Anger F, Paysant F, Brousse F, Le Normand I, Develay P,et al.(2000)Fatal aluminum phosphide poisoning. J Anal Toxicol. Mar; 24(2):90-2

[4]. Meel BL(2011)Aluminium phosphide (tank pill) poisoning in the Transkei region of South Africa: a case report. Med Sci Law. Apr;51(2):116-8.

[5]. Lauterbach M, Solak E, Kaes J, Wiechelt J, Von Mach Ma,et al.(2005) Epidemiology of hydrogen phosphide exposures in humans reported to the poison center in Mainz, Germany, 1983-2003. Clin Toxicol (Phila);43(6):575-81.

[6]. Jakubowicz J, Jakubowicz O, Żaba C, Żaba R, Czarnecka-Operacz M et al.(2010) New legal regulations related to occupational diseases [in Polish]. Post. Derm. Alerg. vol. 27 (2), pp. 122-125.

[7]. Jurek T, Szleszkowski Ł, Maksymowicz K, Wachel K, Drozd R,et al.(2009) Lethal accidents in storage equipment: a report of two cases. Ann Agric Environ Med, 16, 169-172.

[8]. Singh S, Singh D, Wig N, Jit I, Sharma BK,et al.(1996) Aluminum phosphide ingestion: a clinicopathologic study. J Toxicol Clin Toxicol; 34:703-6.

[9]. Bumbrah GS, Krishan K, Kanchan T, Sharma M, Sodhi GS,et al.(2012) Phosphide poisoning: a review of literature. Forensic Sci. Int; 214:1-6.

[10]. Instruction of MPiPS of 18 December, 2002, related to tolerable concentrations of harmful agents in the atmosphere of work [in Polish] (Dz. U. $\mathrm{Nr}$ 217/2002r, poz. 1833) with updates.

[11]. http://www.inchem.org/documents/pims/chemical/pim865.htm.

[12]. Musschoff F, Preuss J, Lignitz E, Madea B(2008)A gas chromatographic analysis of phosphine in biological material in a case of suicide. Forensic Sci. Int; 177 35-38. 